\title{
Hydroboration of Cyclopropane: A Transition State Study
}

\author{
SATYA PRAKASH SINGH* ${ }^{*}$ and POMPOZHI PROTASIS THANKACHAN \\ Department of Chemistry, Indian Institute of Technology Roorkee, Roorkee-247667, India \\ satyapiit@gmail.com
}

Received 22 October 2012 / Accepted 12 November 2012

\begin{abstract}
The hydroboration of cyclopropane has been investigated using the B3LYP density functional method employing several split-valence basis sets. It is shown that the reaction proceeds via a four-centered transition state. Calculations at higher levels of theory were also performed at the geometries optimized at the B3LYP level, but only slight changes in the barriers were observed. Structural parameters for the transition state are also reported.
\end{abstract}

Keywords: Hydroboration, Cyclopropane, Transition state, Propylborane

\section{Introduction}

Hydroboration of alkenes have been investigated theoretically and experimentally. Brown and Zweifel ${ }^{1}$ have shown that the hydroboration of asymmetric alkene yields the antiMarkownikoff addition product predominantly and that the addition takes place at $\beta$-carbon atom. Since the discovery of hydroboration reaction several attempts have been made to explain the reaction mechanism. Brown ${ }^{2}$ experimentally reported that hydroboration reaction proceeds through the intermediate four-centered transition state followed by the formation of addition product. Hydroboration of olefins investigated theoretically. Ab initio molecular orbital study of the hydroboration of ethylene with borane $\left(\mathrm{BH}_{3}\right)$ showed that reaction proceeds through the formation of three-centered intermediate complex followed by the formation of four-centered transition state. In 1990, Wang et al. ${ }^{3}$ have extensively carried out the hydroboration of alkenes, allenes and alkynes and showed that the formation of triangular $\pi$-complex which then deform into the addition product via four-centered transition state. Seyferth ${ }^{4}$ and Streitwieser ${ }^{5}$ on the stereochemical ground predicted the threecentered transition state. The work by Hommes et al. ${ }^{6}$ supports the three-centered nature of transition structure for the hydroboration of ethylene with borane.

In 2011, we have reported the hydroboration of cyclopropane ${ }^{7}$ theoretically at different level of theory and basis set. Triangular $\pi$-complex has been reported with three-centered transition state. In this work it has been considered that borane $\left(\mathrm{BH}_{3}\right)$ approaches along the cyclopropane ring. In the present paper we have reported the result of our investigation of the hydroboration of cyclopropane with borane in which borane moiety approaches cyclopropane ring perpendicularly. 


\section{Computational methods}

All calculations have been performed on a PC running WINDOWS using the Gaussian $98^{8}$ suite of programs. The B3LYP hybrid density functional was used for calculation at DFT ${ }^{9}$ level using several split-valence basis sets. The geometries of the reactants $\left(\mathrm{BH}_{3}\right.$ and $\left.\mathrm{C}_{3} \mathrm{H}_{6}\right)$, transition state and the product were optimized at this level of theory using $6-31 \mathrm{G}^{* *}$, $6-311++G^{* * 10-16}$, cc-pVDZ and AUG-cc-pVTZ ${ }^{17-21}$ basis sets. The nature of each stationary point was confirmed in each case by frequency calculations; all the minima were verified to have all positive frequencies and the transition state to have only one imaginary frequency. MP2 ${ }^{22-26}$ calculations were also performed using the chosen basis sets for comparison purposes. Single point (SP) calculations were also performed at the geometries optimized at the B3LYP/6-31G ${ }^{* *}$ level at the CCSD, CCSD $(T)^{27-31}$, QCISD, QCISD $(T)^{31}$ and MP4D ${ }^{17}$ levels to see if any significant change in the energetics is observed.

\section{Results and Discussion}

When borane approaches a C-C bond of cyclopropane along a line perpendicular to the ring plane no stable intermediate is found. However a transition structure is obtained which is seen to be of the four-centered variety. The geometry of the four-centered transition state optimized at B3LYP/6-31G ${ }^{* *}$ level is shown in Figure 1. The optimized geometrical parameters for the transition state are listed in Table 1.

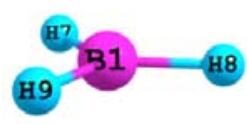

$\mathrm{BH}_{3}$
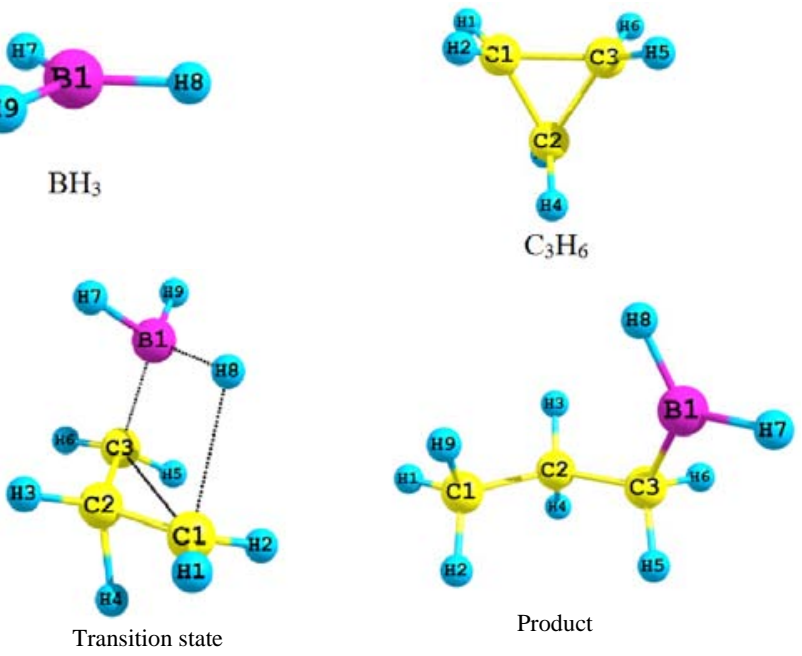

Figure 1. B3LYP/6-31G** optimized geometries of the reactants $\left(\mathrm{BH}_{3}\right.$ and $\left.\mathrm{C}_{3} \mathrm{H}_{6}\right)$, transition state and product

Table 1. Optimized structural parameters (bond lengths in $\AA$ and angles in degree) for the reactants, transition state and product

\begin{tabular}{ccccc}
\hline & $\mathrm{BH}_{3}$ & $\mathrm{C}_{3} \mathrm{H}_{6}$ & Transition State & Product \\
\hline $\mathrm{R}(\mathrm{B} 1-H 7)$ & 1.192 & - & 1.216 & 1.197 \\
$\mathrm{R}(\mathrm{B} 1-H 8)$ & 1.192 & - & 1.281 & 1.198 \\
$\mathrm{R}(\mathrm{B} 1-H 9)$ & 1.192 & - & 1.207 & 2.981 \\
$\mathrm{R}(\mathrm{C} 1-\mathrm{C} 3)$ & - & 1.508 & 2.452 & 2.552 \\
$\mathrm{R}(\mathrm{C} 2-\mathrm{C} 3)$ & - & 1.508 & 1.414 & 1.537 \\
\hline
\end{tabular}




\begin{tabular}{lcccc}
\hline $\mathrm{R}(\mathrm{C} 1-\mathrm{C} 2)$ & - & 1.508 & 1.463 & 1.531 \\
$\mathrm{R}(\mathrm{C} 1-\mathrm{H} 1)$ & - & 1.085 & 1.086 & 1.094 \\
$\mathrm{R}(\mathrm{C} 1-\mathrm{H} 2)$ & - & 1.085 & 1.084 & 1.096 \\
$\mathrm{R}(\mathrm{C} 2-\mathrm{H} 3)$ & - & 1.085 & 1.089 & 1.097 \\
$\mathrm{R}(\mathrm{C} 2-\mathrm{H} 4)$ & - & 1.085 & 1.231 & 1.097 \\
$\mathrm{R}(\mathrm{C} 3-\mathrm{H} 5)$ & - & 1.085 & 1.092 & 1.099 \\
$\mathrm{R}(\mathrm{C} 3-\mathrm{H} 6)$ & - & 1.085 & 1.092 & 1.110 \\
$\mathrm{R}(\mathrm{B} 1-\mathrm{C} 1)$ & - & - & 2.850 & 3.280 \\
$\mathrm{R}(\mathrm{B} 1-\mathrm{C} 3)$ & - & - & 1.716 & 1.559 \\
$\mathrm{R}(\mathrm{C} 1-\mathrm{H} 9)$ & - & - & 2.157 & 1.096 \\
$\angle \mathrm{C} 1 \mathrm{C} 2 \mathrm{C} 3$ & - & 60.0 & 116.8 & 112.5 \\
$\angle \mathrm{C} 2 \mathrm{C} 3 \mathrm{C} 1$ & - & 60.0 & 30.9 & 33.6 \\
$\angle \mathrm{C} 3 \mathrm{C} 1 \mathrm{C} 2$ & - & 60.0 & 32.1 & 33.7 \\
$\angle \mathrm{H} 7 \mathrm{~B} 1 \mathrm{H} 9$ & 119.9 & - & 113.0 & 137.3 \\
$\angle \mathrm{H} 8 \mathrm{~B} 1 \mathrm{H} 9$ & 120.0 & - & 116.4 & 71.8 \\
$\angle \mathrm{H} 8 B 1 H 7$ & 120.0 & - & 105.3 & 118.0 \\
$\angle \mathrm{C} 2 \mathrm{C} 3 B 1$ & - & - & 96.1 & 118.4 \\
$\angle \mathrm{C} 3 B 1 H 9$ & - & - & 111.8 & 68.6 \\
\hline
\end{tabular}

The C1-C3 distance in the transition state is $2.452 \AA$ which is greater than the C1-C3 distance found in the three-centered transition state (1.994 $\AA$ ). In the transition state the forming C1-H8 distance is $2.157 \AA$ which is comparable to forming C1-H9 distance in the three centered transition state. The HOMO of the four-centered transition state is shown in Figure 2. This enables us to visualize the electron density distribution around the forming and breaking bonds.

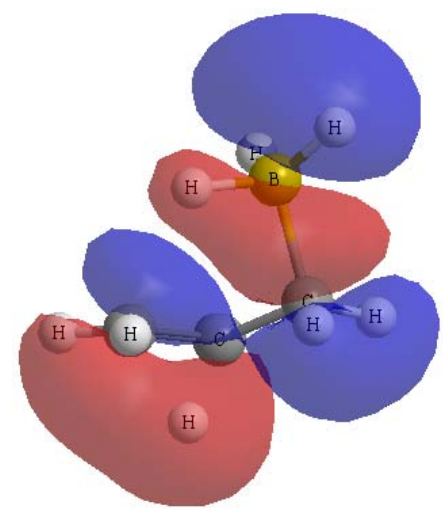

Figure 2. HOMOs of the four-centered transition state for the hydroboration of cyclopropane at B3LYP/6-31G ${ }^{* *}$ level of calculation

The IRC plot for the corresponding four-centered transition state is shown in Figure 3 which shows that the transition state moving downhill towards the reactants on one side and the product the other. Frequency calculation has been performed on the transition state confirms the existence of a single imaginary frequency $\left(1119 \mathrm{~cm}^{-1}\right)$. 


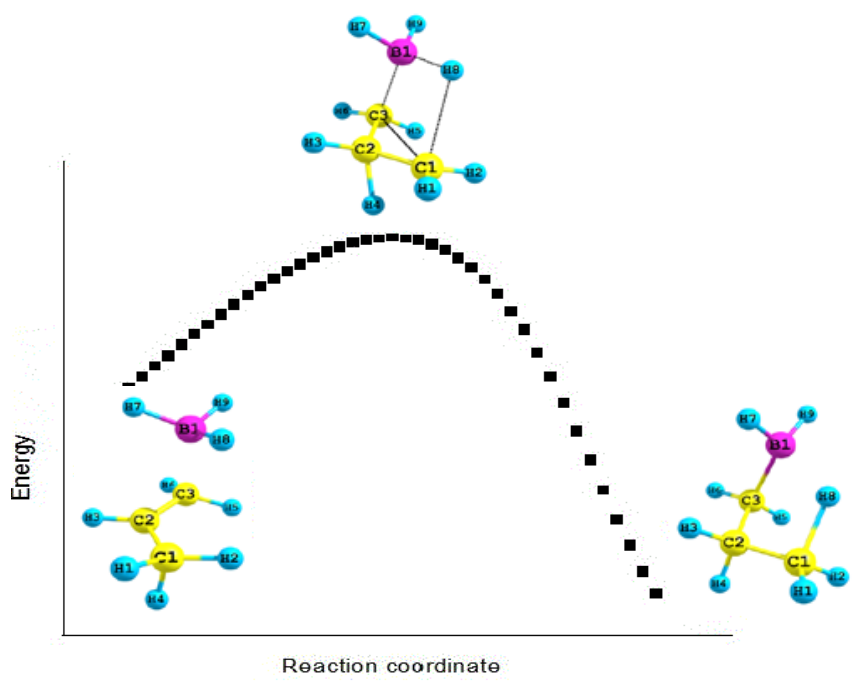

Figure 3. IRC plot for the transition state at the B3LYP/6-31G ${ }^{* *}$ level

Calculations at different levels and with different basis sets have been performed. The total energies (in Hartree) and the relative energies (in $\mathrm{kcal} / \mathrm{mol}$ ) for the reactants, transition state and product are listed in Table 2. Relative energies are shown in Table 3.

We notice that the RHF barriers are significantly higher than the B3LYP or MP2 values in this case also. The four-centered transition state is found to be $44.23 \mathrm{kcal} / \mathrm{mol}$ above the reactant at the B3LYP/6-31G** level making the barrier in this case higher than the energy barrier obtained for the three-centered transition state $(25.95 \mathrm{kcal} / \mathrm{mol})$. Therefore the preferred mechanism is expected to involve the three-centered transition state, though the reaction via the four-centered transition state also should contribute to the overall reaction.

Table 2. Total energies (in Hartree) at different levels and basis sets

\begin{tabular}{cccc}
\hline Method & $\mathrm{BH}_{3}+\mathrm{C}_{3} \mathrm{H}_{6}$ & Transition State & Product \\
\hline RHF/6-31G & -143.4619327 & -143.3599321 & -143.5211937 \\
RHF/cc-pVDZ & -143.4581050 & -143.3622494 & -143.5184661 \\
RHF/6-311++G** & -143.4861062 & -143.3887959 & -143.5451950 \\
RHF/AUG-cc-pVTZ & -143.5025196 & -143.4055783 & -143.5598853 \\
MP2/6-31G & -143.9833023 & -143.9003197 & -144.0464528 \\
MP2/cc-pVDZ & -143.9742346 & -143.9007708 & -144.0397117 \\
MP2/6-311++G ${ }^{* *}$ & -144.0336348 & -143.9585348 & -144.0968889 \\
B3LYP/6-31G ${ }^{* *}$ & -144.5194864 & -144.4489855 & -144.5834724 \\
B3LYP/cc-pVDZ & -144.5074419 & -144.4420096 & -144.5722806 \\
B3LYP/6-311++G ${ }^{* *}$ & -144.5520729 & -144.4835046 & -144.6141527 \\
B3LYP/AUG-cc-pVTZ & -144.5678575 & -144.4994891 & -144.6284606 \\
${ }^{a}$ QCISD/6-31G ${ }^{* *}$ & -144.0404988 & -143.9564109 & -144.1036544 \\
${ }^{a}$ QCISD(T)/6-31G** & -144.0559733 & -143.9769100 & -144.1194505 \\
${ }^{a}$ MP4D/6-31G ${ }^{* *}$ & -144.0458756 & -143.9589953 & -144.1090801 \\
${ }^{a} \mathrm{CCSD} / 6-31 G^{* *}$ & -144.0399797 & -143.9544460 & -144.1030577 \\
${ }^{a} \mathrm{CCSD}(\mathrm{T}) / 6-31 \mathrm{G}^{* *}$ & -144.0557719 & -143.9761424 & -144.1192105 \\
\hline
\end{tabular}

${ }^{a}$ Single point calculations on the B3LYP/6-31G ${ }^{* *}$ structures 
Table 3. Relative energies (in $\mathrm{kcal} / \mathrm{mol}$ ) at different levels and basis sets

\begin{tabular}{|c|c|c|c|}
\hline Method & Reactants & $\Delta \mathrm{E}_{\text {Transition State }}$ & $\Delta \mathrm{E}_{\text {Product }}$ \\
\hline RHF/6-31G ${ }^{* *}$ & 0.00 & 64.00 & -37.18 \\
\hline RHF/cc-pVDZ & 0.00 & 60.15 & -37.87 \\
\hline $\mathrm{RHF} / 6-311++\mathrm{G}^{* *}$ & 0.00 & 61.06 & -37.07 \\
\hline RHF/AUG-cc-pVTZ & 0.00 & 60.83 & -35.99 \\
\hline $\mathrm{MP} 2 / 6-31 \mathrm{G}^{* *}$ & 0.00 & 52.07 & -39.62 \\
\hline MP2/cc-pVDZ & 0.00 & 46.09 & -41.08 \\
\hline $\mathrm{MP} 2 / 6-311++\mathrm{G}^{* *}$ & 0.00 & 47.12 & -39.69 \\
\hline B3LYP/6-31G ${ }^{* *}$ & 0.00 & 44.23 & -40.15 \\
\hline B3LYP/cc-pVDZ & 0.00 & 41.05 & -40.68 \\
\hline B3LYP/6-311++G ${ }^{* *}$ & 0.00 & 43.02 & -38.95 \\
\hline B3LYP/AUG-cc-pVTZ & 0.00 & 42.90 & -31.30 \\
\hline${ }^{a} \mathrm{QCISD} / 6-31 \mathrm{G}^{* *}$ & 0.00 & 52.76 & -39.63 \\
\hline${ }^{a} \mathrm{QCISD}(\mathrm{T}) / 6-31 \mathrm{G}^{* *}$ & 0.00 & 49.61 & -39.83 \\
\hline${ }^{a} \mathrm{MP} 4 \mathrm{D} / 6-31 \mathrm{G}^{* *}$ & 0.00 & 54.51 & -39.66 \\
\hline${ }^{a} \mathrm{CCSD} / 6-31 \mathrm{G}^{* *}$ & 0.00 & 53.67 & -39.58 \\
\hline${ }^{a} \operatorname{CCSD}(\mathrm{T}) / 6-31 \mathrm{G}^{* *}$ & 0.00 & 49.96 & -39.80 \\
\hline
\end{tabular}

The lowest barrier seen is for the B3LYP calculation using the cc-pVDZ basis. The same observation holds for the earlier case also. As the barriers are lower in this case than the 'superior' aug-cc-pVTZ basis also, this might be the optimum basis set to use in studies of reaction pathways with the popular B3LYP functional.

\section{Concluding remarks}

In summary, we have reinvestigated the stationary structures involved in the hydroboration of cyclopropane with borane. Our study posits a four-centered transition state for this reaction in contrast to the earlier study on the hydroboration of cyclopropane, in which three-centered transition state have been reported. However the barrier height for the transition state is found more than the barrier height for the transition state found in the earlier case. No intermediate complex has been observed.

\section{Acknowledgment}

One of the authors (S.P.S.) is grateful to the Ministry of Human Resources and Development (MHRD), Government of India for the award of a fellowship.

\section{References}

1. $\quad$ Brown H C and Zweifel G, J Am Chem Soc., 1959. 81(1), 247-247.

2. Brown H C and Benjamin W A, Hydroboration, New York, 1962.

3. Wang X, Li Y, Wu Y-D, Paddon-Row M N, Rondan N G and Houk K N, J Org Chem., 1990, 55(9), 2601-2609.

4. Seyferth D, Prog Inorg Chem., 1962, 3, 129.

5. $\quad$ Streitwieser A, Jr Verbit L and Bittman R, J Org Chem., 1967, 32(5), 1530-1532.

6. Van Eikema Hommes N J R and Schleyer P V R, J Org Chem., 1991, 56(12), 4074-4076.

7. $\quad$ Singh S P and Thankachan P P, J Mol Model., 2011, 18(2), 751-754.

8. $\quad$ Frisch M J, et al., Gaussian 98, Revision A.7; Gaussian, Inc.: Pittsburgh, PA, 1998.

9. Becke A D, J Chem Phys., 1993, 98(7), 5648-5652.

10. $\quad$ Ditchfield R, Hehre W J and Pople J A, J Chem Phys., 1971, 54(2), 724-728.

11. Hehre W J, Ditchfield R and Pople J A, J Chem Phys., 1972, 56(5), 2257-2261. 
12. Hariharan P C and Pople J A, Molecular Physics, 1974, 27(1), 209-214.

13. Gordon M S, Chem Phys Lett., 1980, 76(1), 163-168.

14. Hariharan P C and Pople J A, Theoretical Chemistry Accounts: Theory, Computation, and Modeling (Theoretica Chimica Acta), 1973, 28(3), 213-222.

15. Clark T, Chandrasekhar J and Schleyer, P V R, J Comp Chem., 1983, 4(3), 294-301.

16. Frisch M J, Pople J A and Binkley J S, J Chem Phys., 1984, 80(7), 3265-3269.

17. Woon D E and Dunning J T H, J Chem Phys., 1993, 98(2), 1358-1371.

18. Kendall R A, Dunning J T H and Harrison R J, J Chem Phys., 1992, 96(9), 6796-6806.

19. Dunning J T H, J Chem Phys., 1989. 90(2), 1007-1023.

20. Peterson K A, Woon D E and Dunning J T H, J Chem Phys., 1994, 100(10), 7410-7415.

21. Wilson A K, van Mourik T and Dunning J T H, J Mol Struct (THEOCHEM), 1996, 388, 339-349.

22. Head-Gordon M, Pople J A and Frisch M J, Chem Phys Lett., 1988, 153(6), 503-506.

23. Frisch M J, Head-Gordon M and Pople J A, Chem Phys Lett., 1990, 166(3), 275-280.

24. Frisch M J, Head-Gordon M and Pople J A, Chem Phys Lett., 1990, 166(3), 281-289.

25. Head-Gordon M and Head-Gordon T, Chem Phys Lett., 1994, 220(1-2), 122-128.

26. Saebo S and Almlof J, Chem Phys Lett., 1989, 154(1), 83-89.

27. Cizek J, Adv Chem Phys., 1969, 14, 35.

28. $\quad$ Purvis Iii G D and Bartlett R J, J Chem Phys., 1982, 76(4), 1910-1918.

29. Scuseria G E, Janssen C L and Schaefer Iii H F, J Chem Phys., 1988, 89(12), 7382-7387.

30. Scuseria G E and Schaefer Iii H F, J Chem Phys., 1989. 90(7), 3700-3703.

31. Pople J A, Head-Gordon M and Raghavachari K, J Chem Phys., 1987, 87(10), 5968-5975. 